\section{USOS Y ABUSOS DEL CORDOBAZO}

USES AND ABUSES OF THE CORDOBAZO

\section{CÉSAR TCACH •}

Investigador Principal del Consejo Nacional de Investigaciones Científicas y Técnicas (CONICET), Centro de Estudios Avanzados (CEA), Universidad Nacional de Córdoba (UNC) (Argentina).

Email: cesartcach@gmail.com

\section{Resumen}

Este artículo analiza los usos del Cordobazo desde una mirada que centra su interés en las percepciones presentes en las distintas culturas y tradiciones políticas argentinas. En función de este imperativo, se estudia el papel de este acontecimiento en las subculturas políticas radical, peronista, de izquierda y de derecha. Se trata de indagar en torno a sus lógicas e hilos conductores con el objeto de avanzar en la dilucidación de los mecanismos de legitimación que cada uno de los actores realizó a partir del uso político del pasado reciente.

\section{Registro bibliográfico}

TCACH, CÉSAR «Usos y abusos del Cordobazo», en: ESTUDIOS SOCIALES, revista universitaria semestral, año XXX, $n^{\circ}$ 58, Santa Fe, Argentina, Universidad Nacional del Litoral, enero-junio, 2020, pp. 183-195.

\section{Abstract}

This article analyzes the uses of the Cordobazo from a perspective that focuses its interest on the perceptions present in the different Argentine cultures and political traditions. Based on this imperative, the role of this event in radical, Peronist, left and right political sub-cultures is studied. It is about investigating their logics and common threads, with the aim of advancing in the elucidation of the legitimation mechanisms that each of the actors carried out from the political use of the recent past.

\section{Descriptores · Describers}

Cordobazo / culturas políticas / legitimación / radicalización / usos del pasado

Cordobazo / political cultures / legitimation / radicalization / uses of the past

Recibido: 15/10/2019 Aprobado: 24 / 01/2020 
Al tenaz pensador de controversias y

debates historiográficos, Eduardo Hourcade

\section{INTRODUCCIÓN}

Desde los trabajos clásicos de Francisco Delich (DELICH, I994, con ediciones previas en 1970,1974 y 1978) y Beba Balbé (BALBÉ, I973 y 1989) hasta otros más recientes (ORTIZ 2019 y SERVETTO-ORTIZ 2OI9), pasando por relevantes contribuciones como las de Mónica Gordillo (GORDILlo, 1994, 1996 y 2008), James Brennan (brennan, 1996) y James Brennan y Gordillo Mónica (BRennan y Gordillo, I994, 2008), o los aportes de Juan Carlos Torre (Torre, 1994), Carlos Altamirano (Altamirano, 1994), Lucio Garzón Maceda (GARZÓn MACEDA, 1994) y otros autores publicados en un célebre número de la revista Estudios en 1994, que dirigía Héctor Schmucler, la rebelión obrera y popular conocida como Cordobazo fue protagonista de apasionados debates ${ }^{1}$. Porque la historia del Cordobazo es también la historia de la lucha por su interpretación, de los usos políticos del pasado reciente y de las memorias inscriptas y resignificadas en las distintas identidades colectivas. Las controversias académicas se cruzaron siempre con debates políticos: si el Cordobazo fue "espontáneo» eso significaba que los sindicatos en su mayoría peronistas, no tuvieron un papel central; si fue organizado, por el contrario, ponía de manifiesto la importancia de los sectores gremiales. Si fue el corolario de un ciclo de luchas previas se reafirman las miradas ancladas en los actores de los '6o; si fue el inicio de un nuevo ciclo marcado por el paradigma de la revolución, el interés se orienta a descubrir lo nuevo, vislumbrando entre sus barricadas la génesis o el potenciamiento de la izquierda revolucionaria y los sectores más contestatarios. En todo caso, cada una de las interpretaciones pone al desnudo la actualidad del pasado. Su mirada, ciertamente condicionada por las preocupaciones e inquietudes del presente, se reflejó en los últimos años —en consonancia con el auge de las reivindicaciones de género y la oleada feminista — en

1] Es el $n^{\circ} 4$ de Estudios, publicada por el Centro de Estudios Avanzados de la Universidad Nacional de Córdoba. 
la génesis de interpretaciones que rescatan el papel de las mujeres en el Cordobazo (FULCHIERI, 2OI8; NOGUERA 2OI9) ${ }^{2}$.

He creído propicio, en este número de la revista Estudios Sociales dedicado a la memoria de Eduardo Hourcade, agudo pensador de problemas y debates historiográficos, centrarme en la deriva política de lo que se ha dicho acerca del Cordobazo. Sin ingenuidad ni candor, ajeno — como lo hubiese hecho Eduardoa las modas de coyuntura y consciente de la dimensión política que involucran los distintos puntos de vista. El objetivo es buscar en cada interpretación sus lados fuertes y sus flancos débiles, identificando las líneas maestras presentes en las miradas de las diversas culturas y tradiciones políticas argentinas. Pero no está el lector en presencia de un estudio pormenorizado o detallado, sino que el interés tiene por puerto entender los hilos conductores que las presiden y les dan inteligibilidad. Utilizando una metáfora pictórica, las distintas formas de interpretar el Cordobazo descansan en una "perspectiva lineal», suponen una construcción de sentido específico que opera como elemento de legitimación. Este estudio, por el contrario, ensaya una suerte de perspectiva aérea intentando, más modestamente, desentrañar las lógicas presentes en cada una de ellas.

2] Estos trabajos han contribuido a identificar su presencia - minoritaria, por cierto- en el sector industrial, sobre todo en las fábricas de vidrio, calzado y alimentación, siendo de particular interés el caso de la fábrica ILASA (Industria Latinoamericana de Accesorios SA) donde la gran mayoría de sus integrantes eran mujeres dedicadas a la elaboración de componentes eléctricos para autos Renault. Cabe añadir, empero, que desde una mirada historiográfica, no se trata de una interpretación feminista del Cordobazo. Los testimonios orales de las mujeres que participaron de ese acontecimiento — presentes en esos estudios - reconocen la prioridad de la dimensión relativa al conflicto de clase. Las reivindicaciones, en todo caso, eran planteadas en términos de la mujer trabajadora. La primera mujer víctima de la dictadura de Onganía fue Hilda Guerrero de Molina, asesinada a raíz de la represión contra los trabajadores de los ingenios azucareros en Tucumán en enero de 1967. Ahora bien, en el universo cultural de las clases medias ilustradas y del movimiento estudiantil algo nuevo en relación a las cuestiones de género comenzaba a incubarse: en 1968 figuraba tercero en el ranking de los libros más leídos en Argentina, La mujer rota, de Simone de Beauvoir (TCACH, 2003: 13). 


\section{CORDOBAZO Y CULTURA DE DERECHA}

Para la cultura de las derechas, el Cordobazo fue la semilla de la subversión y el prólogo de la violencia política que atravesó la Argentina en los años 70. Por cierto, esta mirada tendió a ignorar que el proceso de subversión institucional hundía sus raíces en el golpe militar de 1930. Este proceso tuvo como consecuencia el empoderamiento del factor militar en un doble sentido: el crecimiento de su autonomía institucional en clave corporativa y el aumento de su influencia sobre los procesos de toma de decisiones de los gobiernos civiles (ROUQUIÉ, I986).

En rigor, la participación de los militares en la represión interna fue temprana. En 192I el presidente Yrigoyen envió tropas del ejército al territorio nacional de Santa Cruz para reprimir la rebelión de los trabajadores rurales; en 1945 legitimado por el decreto 536 de Represión de Delitos contra la Seguridad del Estado, el «Comisionado Investigador de Actividades Comunistas» era el comandante de Gendarmería, Miguel Fernández Cristobo, y en 1951 los militares se ocuparon de la represión a los obreros ferroviarios en huelga, al amparo de la Ley de Organización de la Nación para Tiempos de Guerra, promulgada por el presidente Perón en 1948.

Tras el derrocamiento de Perón, este proceso de militarización de la política argentina se profundizó. La lógica corporativa se tradujo en la reivindicación de la soberanía militar, es decir, del derecho a elegir sus propios jefes (del Ejército, de la Fuerza Aérea, de la Marina) y sus propios «representantes» en el gobierno nacional (Secretaría de Guerra, por ejemplo), soslayando que en todos los casos se trataba de atribuciones presidenciales. Las presiones sistemáticas sobre el presidente Frondizi, a la postre también derrocado, fueron su expresión paradigmática. En consonancia con este tipo de práctica política corporativa, las Fuerzas Armadas asumieron una mirada bélica de la política alimentada primero por la influencia de la doctrina de la contrainsurgencia francesa (basada en su experiencia argelina), y posteriormente, por la doctrina de las fronteras ideológicas, promovida por los gobiernos norteamericanos tras el triunfo de la Revolución Cubana.

En 1960, el Comandante de la iv División de Ejército — con sede en Córdoba- general Edgar Joaquín Landa, explicaba: 
«Las fuerzas armadas están en guerra. (...) No reconocer el estado de beligerancia es (...) no participar en lo que debe ser una verdadera cruzada nacional. Desgraciadamente, existen todavía muchos argentinos que se niegan a vivir esta realidad, con lo que cooperan, inconscientemente, con la acción de infiltración del enemigo. Pero, repito, para las Fuerzas Armadas, con o sin apoyo, la lucha contra el comunismo es a muerte. No hay transacciones ni treguas» ${ }^{3}$.

La idea de guerra y de un enemigo interno en el marco de la guerra fría se reflejó con claridad en los manuales de formación de los militares argentinos. Casi un año antes del Cordobazo, el 20 de septiembre de I968, el comandante en jefe del ejército argentino, general Alejandro Agustín Lanusse, firmó una resolución por la cual aprobaba inscribir en el registro de publicaciones militares un libro compuesto de tres tomos denominado Operaciones contra fuerzas irregulares. El tercero tenía circulación restringida, fue incinerado por los golpistas de 1976 y recuperado a raíz de los juicios por violación de los derechos humanos.

Este manual en el que se formaban los oficiales del Ejército, incluía en el abanico de técnicas de la guerra revolucionaria a huelgas, actos de resistencia pasiva, desordenes y «acciones destinadas a arrastrar masas a actos públicos». Promovía, también, la participación de los civiles en la represión, quienes debían participar «con ardor y patriótico desinterés»; más aún preveía la formación de grupos paramilitares: se debía contar con la participación activa del personal civil de las Fuerzas Armadas (médicos, farmacéuticos, ingenieros, etc.) pero también organizar voluntarios para la acción «instruidos física, moral y técnicamente» (TCACH 2015: 155-160). Sin exagerar, es licito suponer que las Fuerzas Armadas argentinas estaban esperando el Cordobazo o un equivalente funcional: en mayo de 1969 funcionaba ya —secretamente- una Comunidad de Inteligencia integrada por integrada por el jefe de policía, el ministro de gobierno, oficiales del Ejército y de la Fuerza Aérea, los rectores de ambas universidades (Rogelio Nores Martínez de la Universidad Nacional de Córdoba y el sacerdote jesuita Fernando Storni de la Universidad Católica de Córdoba); la información que se intercambia era luego remitida al jefe del in Cuerpo de Ejército y finalmente derivada al Poder Ejecuti-

3] Diario Meridiano, 09/07/1960. 
vo Nacional (TCACH, 2OI2: 23I $)^{4}$. En otras palabras, la cooperación civil y militar ya estaba en marcha antes del Cordobazo, imbuida de una lógica schmittiana y decidida a imponer su voluntad, legitimadas por un triple orden de factores: el internacional (la guerra fría), una vocación corporativa robustecida en cada golpe de Estado (1930, 1943, I955, I962 y 1966) y un relato histórico que enaltecía a Ejército e Iglesia Católica como instituciones fundadoras de la patria misma. En el caso de la derecha cordobesa, el mito de la Reforma Universitaria de I9I8 como la semilla de la subversión fue sustituido a partir de 1969, por el del Cordobazo.

\section{CORDOBAZO Y CULTURA DE IZQUIERDA}

Si bien la existencia de pequeñas agrupaciones situadas a la izquierda del Partido Comunista es anterior a mayo de 1969, el Cordobazo marcó un punto de inflexión que dio lugar a un salto cualitativo en un doble sentido: el potenciamiento de las ya existentes y la génesis de una miríada de nuevas organizaciones cuyo horizonte era la revolución socialista. A principios de los años 70 era posible distinguir cuatro grandes franjas: la neoguevarista (el Partido Revolucionario de los Trabajadores —PRT — fundó el Ejército Revolucionario del Pueblo sin renunciar a la idea de la conducción política del partido, aspecto que la diferenció del guevarismo clásico que proponía una guerrilla sin partido), la trotskista (fundamentalmente Política Obrera y el Partido Socialista de los Trabajadores), la maoísta (el Partido Comunista Revolucionario y Vanguardia Comunista, quienes reivindicaban la violencia de masas pero no la guerrilla), y la que se reclamaba fiel al más puro marxismo leninismo (El Obrero, Poder Obrero, las Fuerzas Argentinas de Liberación, entre las principales). Estos cuatro espacios se consideraban a sí mismos como portadores de un proyecto y una práctica política superadora del Partido Comunista. La mayoría de ellos tendieron a descartar la lucha electoral bajo el lema común: «Ni golpe ni elección, Revolución». El Partido Socialista de los Trabajadores (РST) — dirigido por el otrora diputado nacional del Partido Socialista Argentino, Juan Carlos

4] Es posible que en las reuniones hayan participado también personas vinculadas a grandes empresas interesadas en identificar "extremistas». El sitio de las reuniones —según el testimonio de un soldado conscripto en 1969 - era una sede que la Fuerza Aérea tenía en la calle Ituzaingo 558 en el barrio de Nueva Córdoba. 
Coral- optó por participar en las elecciones de marzo de 1973. Todos, empero, podrían compartir las lecciones del Cordobazo en una clave que los emparentaba. Gregorio Flores, dirigente obrero de la FIAT, diría años más tarde:

«El Cordobazo significó (...) un salto en el nivel de conciencia de los trabajadores y desde entonces se convirtió en un símbolo de los explotados (...) mostró la capacidad de lucha de la clase obrera cuando se pone de pié y como puede arrastrar bajo su dirección a otros sectores oprimidos» (FLORES, 2004: 132-I33).

A estas dos conclusiones compartidas se podría añadir una tercera: la legitimidad y viabilidad de la violencia popular frente a la dictadura. En el marco de ese universo de ideas disruptivas, la cultura política de la izquierda tendió muchas veces a soslayar el papel de los dirigentes sindicales peronistas, como Elpidio Torres, secretario general del automotriz sMATA (Sindicato de Mecánicos y Afines del Transporte Automotor), pero también de Miguel Ángel Correa, secretario general del sindicato de la Madera y, a la sazón, de la combativa CGT de los Argentinos en Córdoba. Como recordó oportunamente el sociólogo Francisco Delich, dos semanas antes del levantamiento popular, como respuesta a la represión ejercida contra una asamblea del smata en el célebre estadio Córdoba Sport Club, la regional cordobesa de la CGT de los argentinos expresó en un comunicado: «los obreros saldremos a la calle con las mismas armas que emplean los cipayos de la tiranía. Si tan solo se respeta el derecho de la fuerza, a la fuerza recurriremos para liberar para siempre a nuestra querida patria» (DELICH, I994: 48).

Es posible que el respaldo inicial del sindicalismo peronista al golpe militar del general Onganía — tanto Augusto Timoteo Vandor como José Alonso asistieron de impecable saco y corbata al acto de asunción del dictador, sentándose en un lugar jerárquicamente privilegiado: la segunda fila del Salón Blanco de la Casa Rosada - haya contribuido a facilitar los olvidos del peronismo en las memorias del Cordobazo. Pero también fue el resultado pragmático de la lucha política e ideológica que tuvo como escenario el interior de las fábricas, los sindicatos, cuerpos de delegados y comisiones internas. El propio Gregorio Flores sostuvo que ni el peronismo ni el radicalismo tuvieron «absolutamente nada que ver» con esa experiencia política insurreccional, pese a que luego — admitía — terminaron capitalizando en las urnas la resistencia antidictatorial (FLORES, 2004: I33). 


\section{EL CORDOBAZO EN LA TRADICIÓN PERONISTA}

Elpidio Torres, líder del smata vinculado en el orden nacional a Augusto Timoteo Vandor polemizó en sus memorias - El Cordobazo organizado. La historia sin mitos (TORRES, 1999) — con quienes desde la izquierda académica o política intentaron borrar al peronismo como protagonista del levantamiento popular. Desde su mirada, la exaltación de la figura de Agustín Tosco y la unidad obrero-estudiantil, fueron las llaves maestras que permitieron un desplazamiento interpretativo o bien, una operación historiográfica que secundarizó el papel del sindicalismo peronista y más específicamente, de su sindicato, que agrupaba a los trabajadores de IKARENAULT. Al recordar su vínculo con Tosco, señalaba: «El gringo era un tipo duro en la concepción de sus ideas. A él le molestaba tener que contemporizar conmigo porque no era de su laya política. Ambos nos soportábamos porque sabíamos que no teníamos otro remedio. De una u otra manera, teníamos que hablar de cómo íbamos a enfrentar a nuestros enemigos comunes» (TORRES, 1999: I28). En relación a este recuerdo, justo es señalar el papel central del sMATA en la génesis del Cordobazo. La unidad de acción de su sindicato con Luz y Fuerza formaba parte de una tradición de unidad de acción entre peronistas (sector mayoritario) y marxistas que hundía sus raíces en la normalización de la CGT cordobesa en 1957. Cabe añadir, que Tosco era por entonces, un marxista independiente pero con excelentes relaciones con el Partido Comunista y que Lucio Garzón Maceda —un intelectual socialista - era el abogado del sMATA. Ciertamente, sin el sindicalismo peronista y particularmente el SMATA, el Cordobazo no hubiese sido tal. Elpidio Torres fue condenado a cuatro años de prisión y el «bolche» Agustín Tosco a ocho años por un Consejo de Guerra. En la propia percepción militar, ambos fueron responsables directos de lo ocurrido.

Hubo, empero, otro factor que proveniente de las mismas filas peronistas facilitó el cono de sombra proyectado sobre las relaciones entre peronismo y Cordobazo. Remite a las propias prácticas conmemorativas del peronismo: el 29 de mayo nunca ocupó un lugar simbólico importante en la liturgia peronista. En contraste con las conmemoraciones del I7 de octubre o de los fusilamientos de junio de 1956, el acontecimiento no fue subrayado como una marca indicativa de una construcción 
de sentido correlacionado con su identidad ${ }^{5}$. Este lugar subalterno se asociaba a otro imperativo de ocultamiento: en la cultura política peronista, se tendió a disimular que el Cordobazo fue el principio de un ciclo de radicalización política que implicó grandes cuestionamientos al sindicalismo tradicional. En 1970, dos obreros marxistas — Gregorio Flores y Carlos Masera— ganan la dirección de los sindicatos de la FIAT vinculados a las plantas fabriles de Concord y de Materfer: SITRAC Y SITRAM, que pasaron a asumir un programa que excedía en muchos las reivindicaciones gremiales para sumarse explícitamente a la lucha por una revolución socialista. En 1972, un obrero del PCR (Partido Comunista Revolucionario), Rene Salamanca ganó con su lista Marrón las elecciones del SMATA, siendo reelegido en los comicios de 1974. El clasismo - como corriente sindical que se planteaba de modo explícito la lucha contra el capitalismo y por el socialismo — se extendió a sindicatos grandes (como la uom de Villa Constitución en la provincia de Santa $\mathrm{Fe}$ ) y pequeños, (como los del Caucho y el Calzado en Córdoba). Se hizo presente en grandes ciudades pero también en provincias periféricas como Salta, donde se constituyó una CGT que obedecía a esa orientación. A partir del Cordobazo, además, se produjo un segundo fenómeno social: el peronismo perdió el monopolio de la movilización en las calles. En 1975, la eclosión de coordinadoras obreras interfabriles en el Gran Buenos Aires que agrupaban a cuerpos de delegados y comisiones internas de empresas como Ford, General Motors o Grafa — percibidas por sectores de la izquierda radicalizada como «embriones de soviets»— supuso una inédita movilización social independiente de la estructura institucional de los sindicatos y dirigidas contra un gobierno peronista. La represión parapolicial primero y el golpe militar después, pusieron fin a esa experiencia.

5] El un interesante cotejo de las publicaciones del SMATA, Laura Ortiz destaca el contraste en los modos de conmemoración del Cordobazo en dos épocas distintas: durante la gestión del peronistavandorista Elpidio Torres, la conmemoración del acontecimiento se limitaba a un escueto recordatorio del asesinato de Máximo Mena, a la sazón, obrero de la empresa Renault. A partir de la conducción de Rene Salamanca en 1972, en cambio, pasó a ocupar un lugar central en la memoria promovida desde el sindicato. En 1973 se dedicó un número entero del boletín del gremio en homenaje a ese acontecimiento (ORTIZ, 2018). 


\section{LA MEMORIA RADICAL Y EL CORDOBAZO}

Cinco días antes del Cordobazo, el 24 de mayo de 1969, el Congreso Provincial de Estudio y Actualización Doctrinaria de la UCR, reunido en la localidad serrana de La Cumbre, hacía un diagnóstico de la situación del país. Consideraba que «en el exiguo lapso de tres años, la ocupación extranjera» se había traducido en el control de todos los recursos básicos de la economía nacional, desde el petróleo y la industria automotriz hasta la siderurgia o los frigoríficos. Y añadía, «Indoamérica no podrá madurar sus sueños seculares mientras un solo país hermano permanezca sometido al yugo imperialista». En relación a las formas de lucha para enfrentar a la dictadura y al imperialismo, era contundente: «La instancia electoral ha sido harto escarnecida y clausurada como vía reformista que posibilite la transformación pacífica y progresiva de la estructura. Frente a su ruptura, la Unión Cívica Radical entiende, que solo le queda al pueblo, la salida revolucionaria que no espera la transformación de la vieja estructura: la destruye». El documento delataba el clima de época en el que se inscribía. Argumentaba que el pueblo escucharía esta convocatoria radical para realizar «el cambio, ese cambio que está en todas partes y del que en todas partes se habla y que crece día a día en el corazón angustiado de la sociedad»; un cambo que será «espejo de las aspiraciones de libertad y justicia social» ${ }^{6}$.

En la memoria del radicalismo, el Cordobazo fue una protesta plural que contó con la participación amplia de las clases medias, de algunos dirigentes sindicales vinculados a la UCR — sobre todo en los sindicatos de Prensa y Luz y Fuerza-, evocándose también el importante papel de sus abogados Hipólito Solari Yrigoyen y Mario Abel Amaya, quienes defendieron en los tribunales a Agustín Tosco y otros presos detenidos a raíz del levantamiento popular. En rigor, la participación de las clases medias se vinculó tanto a motivos políticos como económicos. La ley de alquileres había perjudicado a los inquilinos de pequeños comercios, algunos de los cuales debieron cerrar sus puertas; el aumento del Impuesto Inmobiliario había movilizado a los centros vecinales desde principios de 1969, y la agitación estudiantil era como una caja de resonancia que impregnaba el ánimo de los sectores medios. Pero había algo más en el desasosiego que los atravesaba: la dictadura militar había anunciado la firma del certificado de defunción de la democracia pluripartidista, hiriendo profundamente la sensibilidad liberal democrática presente

6] Primer Congreso Provincial de Estudio y Actualización de la UCR. Córdoba, 1969, pp. 1-3 (Documento mecanografiado e impreso). 
en importantes franjas de la sociedad. El diseño corporativista implementado por el gobernador de Onganía en Córdoba, Carlos Caballero, articulaba tres instancias de participación civil controlada: consejos económicos sociales, consejos comunales y comisiones asesoras zonales. En mayo de 1969, el gobernador informó que ya estaban funcionando i80 juntas asesoras ${ }^{7}$. En una carta escrita por Caballero y distribuida entre sus amigos en agosto de 1969, admitía que el movimiento de mayo «arrastró al conjunto de la población», y «sobre todo, a una clase media que demostró el abandono de los valores tradicionales» ${ }^{8}$.

Lo que subyace en las penumbras de la memoria oficial de la UCR son dos elementos relevantes. El primero, que pese al irrumpir de corrientes disruptivas en su interior —en 1967 se forma Resistencia Radical en Córdoba y en 1968 la Junta Coordinadora de la Juventud Radical en Santa Fe- el control político partidario estuvo siempre en manos de una dirección controlada por los sectores moderados. La segunda nota distintiva reside en cierta limitación del fenómeno al acontecimiento, y por ende su reducción a su carácter de protesta democrática y antidictatorial. En consecuencia, al igual que en la memoria peronista, se tendió a disimular su papel de punto de inflexión y elemento catalizador de las tendencias orientadas hacia una transformación radical de la sociedad argentina. Dos años más tarde, el segundo Cordobazo —el Vivorazo — puso blanco sobre negro la fuerte presencia de fuerzas políticas no tradicionales - la izquierda revolucionaria- en la protesta popular. Junto a las consignas antidictatoriales, los políticos tradicionales debieron escuchar otra menos grata: Ni golpe ni elección, Revolución, consigna que fue asumida incluso por los sindicatos de la FIAT: SITRAC y SITRAM ${ }^{9}$.

7] Carlos Caballero fue hasta el momento del golpe de Estado, presidente del Tribunal Superior de Justicia y profesor titular de Doctrina Social de la Iglesia en la Universidad Católica de Córdoba. Su elenco de gobierno estaba constituido por figuras de la elite tradicional cordobesa (TCACH, 2012).

8] Revista Panorama № 147, febrero de 1970, p. 9, Buenos Aires.

9] En marzo de 1971 los cuerpos de delegados de las plantas de Concord y Materfer dieron a conocer una declaración en la que rechazaban tanto el golpe militar como la salida electoral (DUVAL, 2001: 45). El proyecto de declaración presentado por SITRAC-SITRAM al Congreso de Sindicatos Combativos, Agrupaciones Clasistas y Obreros Revolucionarios realizado en Córdoba el 28 de agosto de 1971,expresaba: «La consigna NI GOLPE NI ELECCION, REVOLUCIÓN, coreada por obreros y estudiantes a lo largo y ancho del país, señala el camino propio e independiente del proletariado y de las capas sociales oprimidas hacia la liberación efectiva mediante la legítima violencia revolucionaria organizada que destruya el poder burgués, disuelva a todos los organismos armados al servicio de la represión que ejercen los explotadores e inicie la construcción del socialismo» (FLORES 2004: 229). 


\section{CONCLUSIONES}

Las memorias inscriptas en las diversas culturas políticas subrayan determinados acontecimientos y ocultan otros. Las izquierdas tendieron a subvalorar el papel del peronismo en el Cordobazo; los peronistas omitieron que a partir de entonces, la calle no fue nunca más su monopolio y, más aún, que sus principales dirigentes fueron cuestionados y vilipendiados por masas de trabajadores que los tildaban con el mote despectivo de «burócratas sindicales»; las derechas soslayaron que la idea de una guerra social no fue un producto de mayo de 1969 sino que estaba inscripta en el pensamiento militar, al menos, desde io años antes; y finalmente, el radicalismo tendió a disimular que al abrirse con fuerza el grifo de la radicalización política e ideológica, el cuestionamiento a los «caducos y decrépitos politiqueros de la burguesía» incluía a parte de sus líderes. Balbín como Perón constituían un dique de contención de las masas populares en la mirada de la izquierda revolucionaria, envuelta en el torbellino de una crisis de crecimiento en los primeros años 70.

En contraste con la mirada de Ernesto Laclau (2012) que consideraba que la lucha por el retorno de Perón era el elemento unificador del campo popular, en I969 la consigna no fue «Perón vuelve» sino "Abajo la dictadura». Al fin de cuentas, el propio Onganía había unificado al Ejército reemplazado el antiperonismo por la antipolítica y el antipartidismo. En 1970, la constitución de la alianza radicalperonista «La Hora del Pueblo» intentó, doblemente, poner fin a esa ilusión y conjurar, sin éxito a la postre, la creciente radicalización política que el Cordobazo, como una caja de Pandora había contribuido a diseminar. 


\section{Referencias bibliográficas}

ALTAMIRANO, CARLOS (1994): «Memoria del 69», en: Estudios, $\mathrm{n}^{\circ} 4$, pp. 15-24.

BALVÉ, BEBA et al. (1973): Lucha de calles, lucha de clases (Córdoba 1971-1969), Buenos Aires, La Rosa Blindada.

BALVÉ, BEBA et al. (1989): El 69. Rosariazo-Cordobazo-Rosariazo. Huelga política de masas, Buenos Aires, Contrapunto-CICSO.

BRENNAN, JAMES (1996): El Cordobazo: las guerras obreras en Córdoba, 1955-1976, Buenos Aires, Sudamericana.

BRENNAN, JAMES Y GORDILLO, MONICA (1994): «Protesta obrera, rebelión popular, insurrección urbana en la Argentina: el Cordobazo», en: Estudios, $n^{\circ} 4$, pp. 51-74.

BRENNAN, JAMES Y GORDILLO, MONICA (2008): Córdoba rebelde: el Cordobazo, el clasismo y la movilización social, La Plata, De La Campana.

DELICH, FRANCISCO (1994): Crisis y protesta social: Córdoba 1969. CEA/UNC.

DUVAL, NATALIA (2001): Los sindicatos clasistas: SITRAC, Córdoba, Fundación Pablo Milesi.

FLORES, GREGORIO (2004): SITRAC-SITRAM: la Iucha del clasismo contra la burocracia sindical, Córdoba, Espartaco.

FULCHIERI, BIBIANA (2018): El Cordobazo de las mujeres, Córdoba, Las Nuestras/Agencia Córdoba Cultura.

GARZON MACEDA, LUCIO (1994): «El Cordobazo: algunos de sus mitos y leyendas», en: Estudios, no 4, pp. 15-24.

GORDILLO, MONICA (1996): Córdoba en los '60: la experiencia del sindicalismo combativo, Dirección General de Publicaciones, Universidad Nacional de Córdoba.
LACLAU, ERNESTO (2012): La razón populista, Buenos Aires, Fondo de Cultura Económica.

NOGUERA, ANA (2019): Revoltosas y revolucionarias: mujeres y militancia en la Córdoba setentista, Córdoba, Universidad Nacional de Córdoba.

ORTIZ, LAURA (2018): «Identidades obreras: el clasismo y sus representaciones», en: Sociohistórica, $n^{\circ} 41$, pp. 1-11.

ORTIZ, LAURA (2019): Con los vientos del Cordobazo. Los trabajadores clasistas en tiempos de violencia y represión, Córdoba, Universidad Nacional de Córdoba.

ROUQUIÉ, ALAIN (1986): Poder militar y sociedad política en la Argentina: Práctica y mecanismos del poder militar. Anatomía del poder militar, ensayo de interpretación, Buenos Aires, Hyspamérica.

SERVETTO ALICIA Y ORTIZ, LAURA (2019): «La memoria como boomerang ¿Qué queda del Cordobazo?», en: Contenciosa, no 9, pp. 1-15.

TCACH, CESAR (2003): La política en consignas. Memoria de los setenta, Rosario, Homo Sapiens. TCACH, CESAR (2012): De la Revolución Libertadora al Cordobazo: Córdoba, el rostro anticipado del país, Buenos Aires, Siglo XXI.

TCACH, CESAR (2015): «Educar para la guerra: manuales militares reservados e incinerados en Argentina (1968-1976)», en: Cuadernos de Historia. Serie Economía y Sociedad, no 13/14, 151-168. TCACH, CESAR (2019): «Una protesta que se conjuga en plural», en: La Voz del Interior, 26/05/2019 Córdoba.

TORRE, JUAN CARLOS (1994): «A partir del Cordobazo», en: Estudios, n 4 , pp. 15-24.

TORRES, ELPIDIO (1999): El Cordobazo organizado: la historia sin mitos, Córdoba, Catálogos. 